Goldschmidt 2021 Abstract

https://doi.org/10.7185/gold2021.8183

\section{Heterophase boundaries, chemical- mechanical potentials, plastic instability and trace-element behavior in upper-mantle assemblages: Application of Atom Probe Tomography to the understanding of crystal-boundary dynamics}

\author{
JOSEPH CUKJATI ${ }^{1}$, REID COOPER ${ }^{1}$, PROF. STEVE \\ PARMAN, PHD ${ }^{1}$, NINGLI ZHAO ${ }^{1}$, AUSTIN AKEY ${ }^{2}$ AND \\ FERNANDO LAIGINHAS ${ }^{3}$ \\ ${ }^{1}$ Brown University \\ ${ }^{2}$ Harvard University \\ ${ }^{3} \mathrm{U}$ Alabama, Tuscaloosa \\ Presenting Author: stephen_parman@brown.edu
}

Olivine-pyroxene heterophase boundaries play a significant role in effecting plastic instability in upper-mantle rock, specifically through their impact on increasing the kinetics of chemical-diffusion processes active in phase-boundary sliding. Experimental rheological studies emphasizing the role of grain and heterophase boundary processes demonstrate conclusively that microstructure of olivine-pyroxene aggregates evolve during deformation to optimize the density of heterophase boundaries and so lower the effective viscosity. Stress-induced chemical reactions, in which olivine is transformed into pyroxene on boundaries having a specific orientation relative to the stress tensor and pyroxene is transformed into olivine on the geometrically complementary boundaries, allow the aggregates to have an effective viscosity that is an order of magnitude lower than either pure olivine or pure pyroxene aggregates of similar grain sizes [1,2].

We investigated both grain and heterophase boundaries of deformed olivine-clinopyroxene (synthetic wehrlite) aggregates at the $<1$-to-10-nm scale to understand how ionic flow in both grain/heterophase boundaries and in the crystals meeting at the boundaries links to the macro-scale, 'bulk rock' mechanical dynamics [3]. This talk focuses on the results from our Atom Probe Tomography (APT) characterizations (Fig. 1 APT image of $\mathrm{Ca}$ atoms along olivine-olivine grain boundary). Evidence of the deformation effecting phase conversion from olivine to clinopyroxene - and vice versa - is revealed by APT as subtle chemical gradients in the near-boundary composition of the pyroxene. These chemical gradients are linked to the local stress state and highlight one, compelling application of APT towards understanding deformation mechanisms. Implication for deformation-affected distributions of incompatible trace elements and their impact, e.g., on the chemical signature of melting, will be discussed.

References:

[1] Sundberg M, Cooper RF (2008) Crystallographic preferred orientation produced by difusional creep of harzburgite: efects of chemical interactions among phases during plastic flow. J Geophys Res Solid Earth 113(12):B12208.
[2] Zhao N, Hirth G, Cooper RF, Kruckenberg SC, Cukjati J (2019) Low viscosity of mantle rocks linked to phase boundary sliding. Earth Planet Sci Lett 517:83-94.

[3] Cukjati J.T., Cooper R.F., Parman S.W., Zhao N., Akey A.J. and Laiginhas F.A.T.P (2019) Differences in chemical thickness of grain and phase boundaries: an atom probe

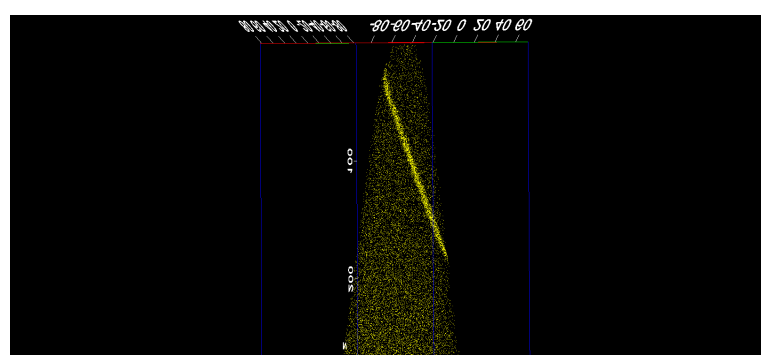

